\title{
Postsurgical bile duct disruption: Digital single-operator cholangioscopy-assisted recanalization
}

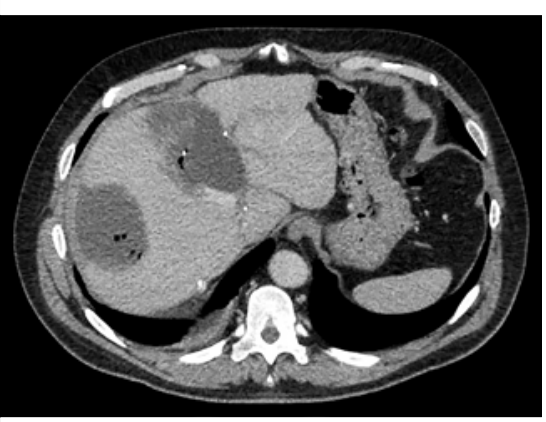

Fig. 1 Computed tomography scan, axial section, showing subhepatic collections compatible with bilomas.

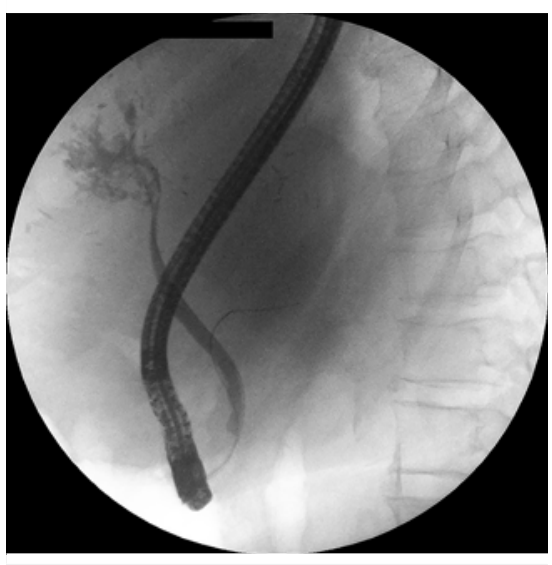

> Fig. 2 Fluoroscopy during endoscopic retrograde cholangiopancreatography showing common bile duct stenosis and biliary leak. The intrahepatic bile duct shows no opacification. Second guide in the main pancreatic duct (double-guidewire technique).

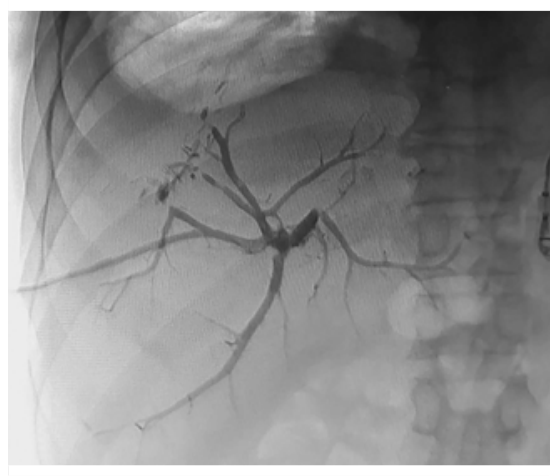

- Fig. 3 Fluoroscopy during percutaneous transhepatic cholangiography showing dilated intrahepatic bile ducts. The extrahepatic bile duct shows no opacification.
Treatment of postsurgical biliary leaks is complex and depends on their severity. Endoscopic treatment is usually preferred, but it can be difficult in cases of complete duct transection. However, most patients with a biliary leak are septic and are therefore not eligible for a surgical approach [1, 2, 3].

We present the case of a 59-year-old patient who developed jaundice and fever 10 days after a hepatic metastasectomy (segments II and IVa). A computed tomography (CT) scan showed a 14-cm perihepatic collection, compatible with an infected biloma ( $\mathbf{F i g} \mathbf{1} \mathbf{1}$ ).

Endoscopic retrograde cholangiopancreatography (ERCP) demonstrated a stenosis of the proximal common bile duct (CBD), a biliary leak, and no opacification of the intrahepatic bile duct (> Fig.2). A sphincterotomy was performed and two transpapillary nasobiliary drainage catheters (7F and 8.5F) were placed. The biloma was percutaneously drained. Cannulation of the CBD 1 month later was not successful using a radiological approach with percutaneous transhepatic cholangiography (> Fig. $\mathbf{3}$ ).

A combined percutaneous and endoscopic treatment was planned (\Fig.4, - Video 1). The stenosis of the CBD was dilated and a cholangioscope was introduced in the collection via ERCP. A guide was advanced via percutaneous transhepatic cholangiography, captured within the collection with direct vision using a snare, and advanced to the duodenum. With maintained endoscopic traction of the guide, a percutaneous $8.5 \mathrm{~F}$ plastic catheter was inserted, with the proximal fenestrated portion in the intrahepatic bile duct and the distal fenestrated portion in the CBD. Finally, a plastic biliary stent $(9 \mathrm{~cm} / 10 \mathrm{~F})$ was placed. Fluoroscopic control images showed continuation between the intrahepatic and common bile duct (> Fig.5). The plastic catheter was exchanged for a biodegradable biliary stent 6 weeks later. Final recanalization was achieved.

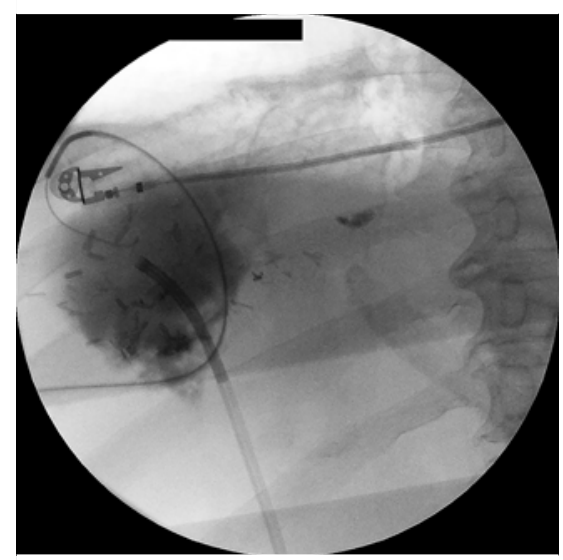

> Fig. 4 Combined-approach fluoroscopy. The intraductal cholangioscope captures a percutaneous transhepatic guide within the biloma.

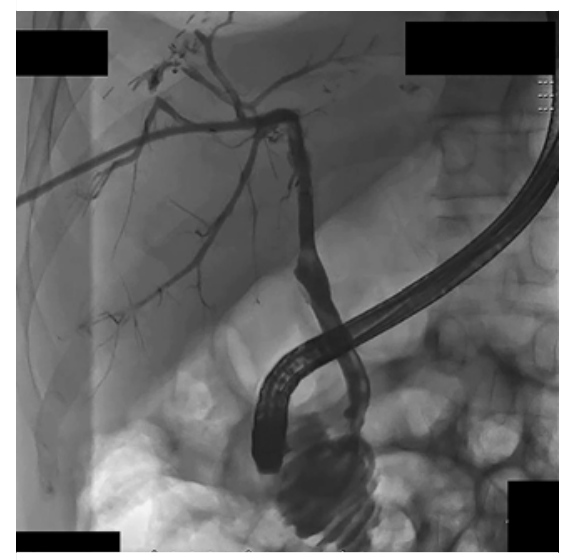

> Fig. 5 Post-treatment fluoroscopic control showing continuity between the intrahepatic and extrahepatic bile ducts and resolution of the biliary leak.

Biodegradable biliary stents show good technical and clinical success in biliary fistula treatment [4]. In this case, the cholangioscope was the key element for the described rendezvous, illustrating the diagnostic and therapeutic advantages of direct visualization of the biliary duct [5]. A multidisciplinary approach is crucial for a good clinical outcome in these challenging cases $[2,3]$.

Endoscopy_UCTN_Code_TTT_1AR_2AK 


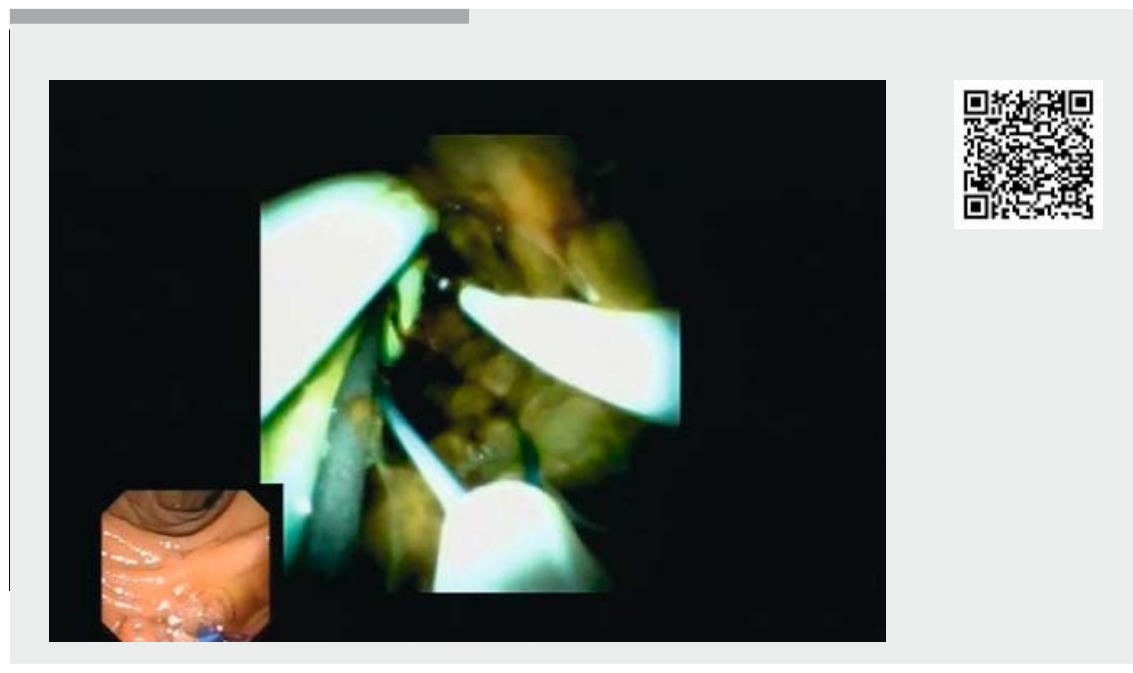

Video 1 Spyglass cholangioscopy-assisted rendezvous in postsurgical bile duct disruption. We combined a radiologic approach via percutaneous transhepatic cholangiography with an endoscopic approach via endoscopic retrograde cholangiopancreatography and intraductal cholangioscopy, achieving reconnection of the bile ducts.

\section{Competing interests}

The authors declare that they have no conflict of interest.

The authors

Carolina G. González-Olivares ${ }^{1}$, José R. Foruny ${ }^{1}$, Andreína Olavarría², Juan Ángel González Martín', Sergio López-Durán', Enrique Vázquez-Sequeiros ${ }^{1}$, Agustín Albillos

1 Gastroenterology and Hepatology Department, University Hospital Ramón y Cajal, IRYCIS, University of Alcalá, CIBEREHD, Madrid

2 Radiology Department, University Hospital Ramón y Cajal, Madrid
[3] Popat B, Thakkar D, Deshmukh H et al. Percutaneous transhepatic biliary drainage in the management of post-surgical biliary leaks. Indian J Surg 2017; 79: 24-28

[4] Siiki A, Vaalavuo Y, Antila A et al. Biodegradable biliary stents preferable to plastic stent therapy in post-cholecystectomy bile leak and avoid second endoscopy. Scand J Gastroenterol 2018; 53: 1376-1380

[5] Navaneethan U, Moon JH, Itoi T. Biliary interventions using single-operator cholangioscopy. Dig Endosc 2019; 31: 517-526

\section{Bibliography}

Endoscopy 2021; 53: 764-765

DOI 10.1055/a-1258-4176

ISSN 0013-726X

published online 1.10 .2020

(c) 2020. Thieme. All rights reserved.

Georg Thieme Verlag KG, Rüdigerstraße 14, 70469 Stuttgart, Germany

\section{ENDOSCOPY E-VIDEOS}

https://eref.thieme.de/e-videos

\section{Corresponding author}

\section{José R. Foruny, MD}

Servicio de Gastroenterología y Hepatología, Hospital Universitario Ramón y Cajal, Carretera de Colmenar Viejo km. 9,100, 28034 Madrid, Spain Fax: +34-913368000

forunyj@yahoo.es

\section{References}

[1] Navarrete C, Gobelet JM. Treatment of common bile duct injuries after surgery. Gastrointest Endosc Clin N Am 2012; 22: 539-553

[2] Nuzzo G, Giuliante F, Giovannini I et al. Advantages of multidisciplinary management of bile duct injuries occurring during cholecystectomy. Am J Surg 2008; 195: 763-769

\section{CORRECTION}

Postsurgical bile duct disruption:

Digital single-operator

cholangioscopy-assisted

recanalization

González-Olivares CG, Foruny JR,

Olavarría A et al. Postsurgical bile duct disruption: Digital single-operator cholangioscopy-assisted recanalization. Endoscopy 2020, 52:

10.1055/a-1258-4176

In the above-mentioned article, the title has been corrected. Correct is: Postsurgical bile duct disruption: Digital single-operator cholangioscopyassisted recanalization. This was corrected in the online version on May 6, 2021. 